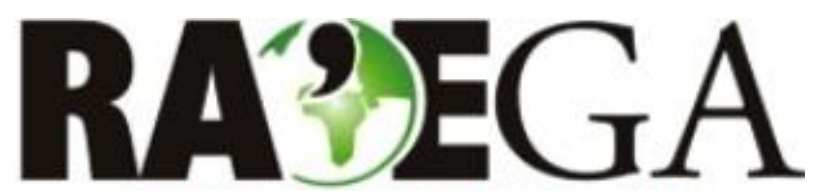

O ESPACYO GEOGRAFICO EM ANÁLISE

\title{
QUANTIFICAÇÃO E ANÁLISE DA GEODIVERSIDADE APLICADA AO GEOTURISMO NA ÁREA DE PROTEÇÃO AMBIENTAL SUL DA REGIÃO METROPOLITANA DE BELO HORIZONTE, MINAS GERAIS
}

\section{GEODIVERSITY'S QUANTIFICATION AND ANALYSIS APPLIED TO GEOTOURISM IN THE SOUTHERN ENVIRONMENTAL PROTECTION AREA OF THE METROPOLITAN REGION OF BELO HORIZONTE, MINAS GERAIS}

\author{
Eric Oliveira Pereira \\ Programa de Pós-Graduação em Geografia da Universidade Federal \\ de Minas Gerais - UFMG \\ Belo Horizonte, MG, Brasil \\ e-mail: ericpereiraufmg@gmail.com \\ Úrsula Ruchkys \\ Departamento de Cartografia do Instituto de Geociências da \\ Universidade Federal de Minas Gerais - UFMG \\ Belo Horizonte, MG, Brasil \\ e-mail:tularuchkys@yahoo.com.br
}

\section{Recebido em: 04/06/2015}

Aceito em: 15/06/2016

\section{Resumo}

A Área de Proteção Ambiental Sul da Região Metropolitana de Belo Horizonte (APA Sul da RMBH), localizada no Quadrilátero Ferrífero, Minas Gerais, é uma importante unidade de conservação de manejo sustentável. O presente estudo teve como objetivo quantificar a geodiversidade da área da pesquisa de forma a selecionar locais de maior potencial para 0 desenvolvimento do geoturismo. O mapeamento da quantificação foi fundamentado em índices de diversidade natural e em técnicas de geoprocessamento. Foram usados os mapas de geologia, pedologia, geomorfologia e hidrogeologia na escala 1:50.000. O índice de geodiversidade foi calculado considerando o número de feições das seguintes variáveis: litologia, idade geológica, unidades de solo, unidades de relevo, unidades morfológicas e unidades hidrogeológicas. O mapa síntese da quantificação da geodiversidade foi reclassificado em quatro classes: muito alta, alta, média e 
baixa. A maior parte da área está classificada como de alta geodiversidade e essa classe está espacialmente bem distribuída por toda a APA. Já a classe muito alta geodiversidade está espacialmente concentrada em quatro regiões distintas. Em cada uma dessas regiões foi selecionado um geosítio que foi descrito em relação a seu potencial para uso geoturístico.

Palavras chaves: geodiversidade; geopatrimônio; Quadrilátero Ferrífero

\begin{abstract}
The Southern Environmental Protection Area of the Metropolitan Region of Belo Horizonte (APA Sul da RMBH), located in the Iron Quadrangle (Quadrilátero Ferrífero), Minas Gerais, is an important sustainable management conservation unit. This paper aimed to quantify the study area's geodiversity so that locations with higher potential for geoturism were selected. The quantification's mapping was based on natural diversity indexes and geoprocessing techniques. Geology, pedology, geomorphology and hydrogeology maps in the scale of 1:50000 were used. The geodiversity index was calculated considering the number of of features of the following variables: lithology, geological age, soil categories, landscape units, morphological units and hydrogeological units. The geodiversity quantification summary map was reclassified in four categories: very high, high, medium and low. The larger part of the area is classified as high geodiversityand this category is well distributed throughout the entire APA. The very high geodiversity category is spatially concentrated in four distinct regions. In each one of those regions a geosite was selected and described in relation to its potential for geoturism.
\end{abstract}

Key words: geodiversity; geoheritage; Quadrilátero Ferrífero

\title{
1. INTRODUÇÃO
}

A diversidade natural pode ser entendida como a integração das componentes biótica (biodiversidade) e abiótica (geodiversidade) da natureza. O termo geodiversidade se consolidou a partir dos anos 2000, tendo sido utilizado pela primeira vez em 1991, durante um encontro internacional sobre geoconservação, com a exposição oral proferida por M. Stanley (BUREK; POTTER, 2002; CARCAVILLA URQUI, 2006, p.07).

Na literatura internacional, Stanley (2000, p.15), estabeleceu o conceito de geodiversidade adotado pela Royal Society for Nature Conservation do Reino Unido como sendo a variedade de ambientes geológicos, fenômenos e processos ativos que dão origem a paisagens, rochas, minerais, fósseis, solos e outros depósitos superficiais que são o suporte para a vida na Terra. Para 
Gray (2004, p. 8) a geodiversidade é "a diversidade natural de características geológicas (rochas, minerais e fósseis), geomorfológicas (formas de relevo e processos) e pedológicas, que inclui suas relações, propriedades, interações e sistemas".

No contexto brasileiro, vários cientistas se envolveram na elaboração de definições. Oliveira et al. (2013) fazem uma revisão conceitual sobre geodiversidade e sua associação com o patrimônio geomorfológico e geoconservação onde discutem os caminhos a serem seguidos por esse tipo de estudo no Brasil. Veiga (1999, p.88-89) apresenta o conceito de geodiversidade como a expressão das particularidades do meio físico de uma determinada região geográfica e leva em consideração a litologia, a geomorfologia, o clima, o solo e as águas. Além disso, afirma que a geodiversidade condiciona a morfologia da paisagem, a diversidade biológica e cultural. Para o Serviço Geológico do Brasil - CPRM (2006), a geodiversidade diz respeito à variedade de ambientes, composição, fenômenos e processos geológicos que dão origem à natureza abiótica (meio físico), tendo valores intrínseco, cultural, estético, econômico, científico, educativo e turístico.

A geodiversidade pode ser estudada de forma qualitativa e/ou quantitativa. Estudos qualitativos se baseiam na descrição e análise dos valores da geodiversidade e podem ser vistos em Bento e Rodrigues (2011), Borba (2011), Ruchkys et al. (2015) dentre outros. As abordagens quantitativas têm sido desenvolvidas com uso de técnicas de geoprocessamento e, segundo Pereira (2014, p.14), esse tipo de avaliação derivou, em parte, das experiências com a quantificação da biodiversidade que usa índices como os de Shannon e de Simpson para seu cálculo. Gorenstein (2009, p.20) afirma que o índice de Shannon vem da teoria da informação e busca medir o grau de incerteza na predição correta da espécie a que pertence o próximo indivíduo coletado em uma amostragem sucessiva. O índice de Simpson é originado da teoria da probabilidade, e sua unidade resultante pode ser entendida como a probabilidade em se coletar aleatoriamente dois indivíduos de uma comunidade, desde que pertencentes a espécies diferentes. Para Pereira et al. 
(2013) e Pereira (2014), ao trazer estes índices de diversidade para a geodiversidade, é possível calcular sua riqueza e abundância.

A quantificação da geodiversidade geralmente é realizada com aplicação de algoritmos e do uso de índices que envolvem diferentes metodologias. Um dos estudos pioneiros foi de Kozlowski (2004) que, para elaborar o Atlas da Geodiversidade da Polônia utilizou os seguintes elementos: litologia, relevo, solos, águas superficiais e uso do solo. Vários estudos se seguiram com destaque para: Serrano e Ruiz Flaño (2007), que mensuraram a geodiversidade da Espanha por meio de um índice que relaciona a variabilidade dos elementos abióticos com um coeficiente de rugosidade do relevo e as unidades de paisagem onde esses elementos estão distribuídos; Hjort e Luoto (2010), que, a partir da adaptação do trabalho de Serrano e RuizFlaño (2007), calcularam o índice de geodiversidade para as paisagens de altas latitudes, no norte da Finlândia.

No Brasil, o pioneirismo nos estudos relacionados aos índices de geodiversidade foi feito com o uso do software SAGA na Universidade Federal do Rio de Janeiro, com as pesquisas de Xavier-da-Silva et al. (2001). Estes autores geraram índices de geodiversidade específica, múltipla e múltipla ponderada, para a bacia do rio Guandu, no Rio de Janeiro com análise integrada dos seguintes elementos abióticos: solos, geomorfologia, litologia, alinhamentos geológicos e geomorfológicos; além da fitoecologia. Merecem destaque ainda os trabalhos mais recentes de Silva (2012), Manosso e Ondicol (2012), Arruda (2013), Pereira (2014) e os mapas estaduais de geodiversidade gerados pela CPRM.

A quantificação da geodiversidade tem várias aplicações permitindo, por exemplo, identificar em um dado território, áreas prioritárias para geoconservação ou com maior potencial para o desenvolvimento do geoturismo, segmento do turismo que faz uso do geopatrimônio como atrativo. Para Bento e Rodrigues (2013), geoturismo e geoconservação podem também ser tomados como indutores do desenvolvimento econômico local, propiciando a gestão e utilização da geodiversidade, desde que realizada de forma planejada e sustentável. Como os sítios do geopatrimônio podem ser usados 


\title{
QUANTIFICAÇÃO E ANÁLISE DA GEODIVERSIDADE APLICADA AO GEOTURISMO NA ÁREA DE PROTEÇÃO AMBIENTAL SUL DA REGIÃO METROPOLITANA DE BELO HORIZONTE, MINAS GERAIS
}

para fins científicos, turísticos e/ou educativos, Brilha (2015) propõe a utilização do termo sítios da geodiversidade para aqueles que tenham valores turísticos, didáticos e/ou educativos, excluindo desta definição os sítios do geopatrimônio que tem valor exclusivamente científico.

O geoturismo é um segmento do turismo que teve sua definição desenvolvida a partir de meados da década de 1990 pelo pesquisador inglês Thomas Hose como sendo: "a provisão de serviços e facilidades interpretativas que permitem aos turistas adquirirem conhecimento e entendimento da geologia e geomorfologia de um sítio, além de mera apreciação estética" (HOSE, 1995, p.17). Na década seguinte Hose (2000, p.136) faz uma revisão de sua definição original de 1995 e passa a usar o termo geoturismo para designar:

A provisão de facilidades interpretativas e serviços para promover o valor e os benefícios sociais de lugares e materiais geológicos e geomorfológicos e assegurar sua conservação, para uso de estudantes, turistas e outras pessoas com interesse recreativo ou de lazer (HOSE, 2000, p.136).

No Brasil o geoturismo foi definido por Ruchkys (2007) e por Silva e Perinotto (2007). Para Ruchkys (2007) o geoturismo é:

\begin{abstract}
Um segmento da atividade turística que tem o patrimônio geológico como seu principal atrativo e busca sua proteção por meio da conservação de seus recursos e da sensibilização do turista, utilizando, para isto, a interpretação deste patrimônio tornando-o acessível ao público leigo, além de promover a sua divulgação e o desenvolvimento das Ciências da Terra (RUCKHYS, 2007, p. 23).
\end{abstract}

Silva e Perinotto (2007) definiram geoturismo como:

\begin{abstract}
A atividade do turismo com conotação geológica, ou seja, a visita organizada e orientada a locais onde ocorrem recursos do meio físico geológico que testemunham uma fase do passado ou da história da origem e evolução do planeta Terra. Também se inclui, nesse contexto, o conhecimento científico sobre a gênese da paisagem, os processos envolvidos e os testemunhos registrados em rochas, solos e relevos (SILVA; PERINOTTO, 2007, não paginado).
\end{abstract}

Segundo Ruban (2015) o Brasil se destaca mundialmente no desenvolvimento de pesquisas envolvendo esse segmento, ficando em 
segundo lugar no ranking mundial logo depois da Itália. Em seu artigo, o autor faz uma análise das publicações entre os anos de 2012 e 2014 e destaca as pesquisas brasileiras de Lopes et al. (2012), Bento et al. (2012), Liccardo et al. (2012), Ostanello et al. (2012), Mantesso-Neto et al. (2012), Moreira (2012), Campello et al. (2012), Lobo e Boggiani (2013), Mansur et al. (2013), Salamuni et al. (2013), Ruchkys e Machado (2013), dentre outros.

A partir destas considerações, este artigo tem como principal objetivo apresentar o uso de mapeamento quantitativo da geodiversidade na seleção de áreas prioritárias para o desenvolvimento do geoturismo na região da Área de Proteção Ambiental Sul da Região Metropolitana de Belo Horizonte (APA Sul da RMBH). Conforme já salientado por Ruchkys (2009) e Ruchkys e Machado (2013) essa é uma região privilegiada pela sua geodiversidade e geopatrimônio com grande potencial para o desenvolvimento do geoturismo.

\section{2. ÁREA DE ESTUDO}

A APA Sul da RMBH está localizada na porção centro-sudeste do Estado de Minas Gerais, ao sul de Belo Horizonte, inserida no Quadrilátero Ferrífero (QF), importante distrito metalogenético do Brasil. Seus limites territoriais abrangem parte dos seguintes municípios: Belo Horizonte, Ibirité, Sarzedo, Mário Campos, Brumadinho, Raposos, Nova Lima, Itabirito, Caeté, Santa Bárbara, Barão de Cocais e Catas Altas, além da totalidade do município de Rio Acima. Compreendendo um total de aproximadamente $1.624 \mathrm{~km}^{2}$ (Figura 1). 


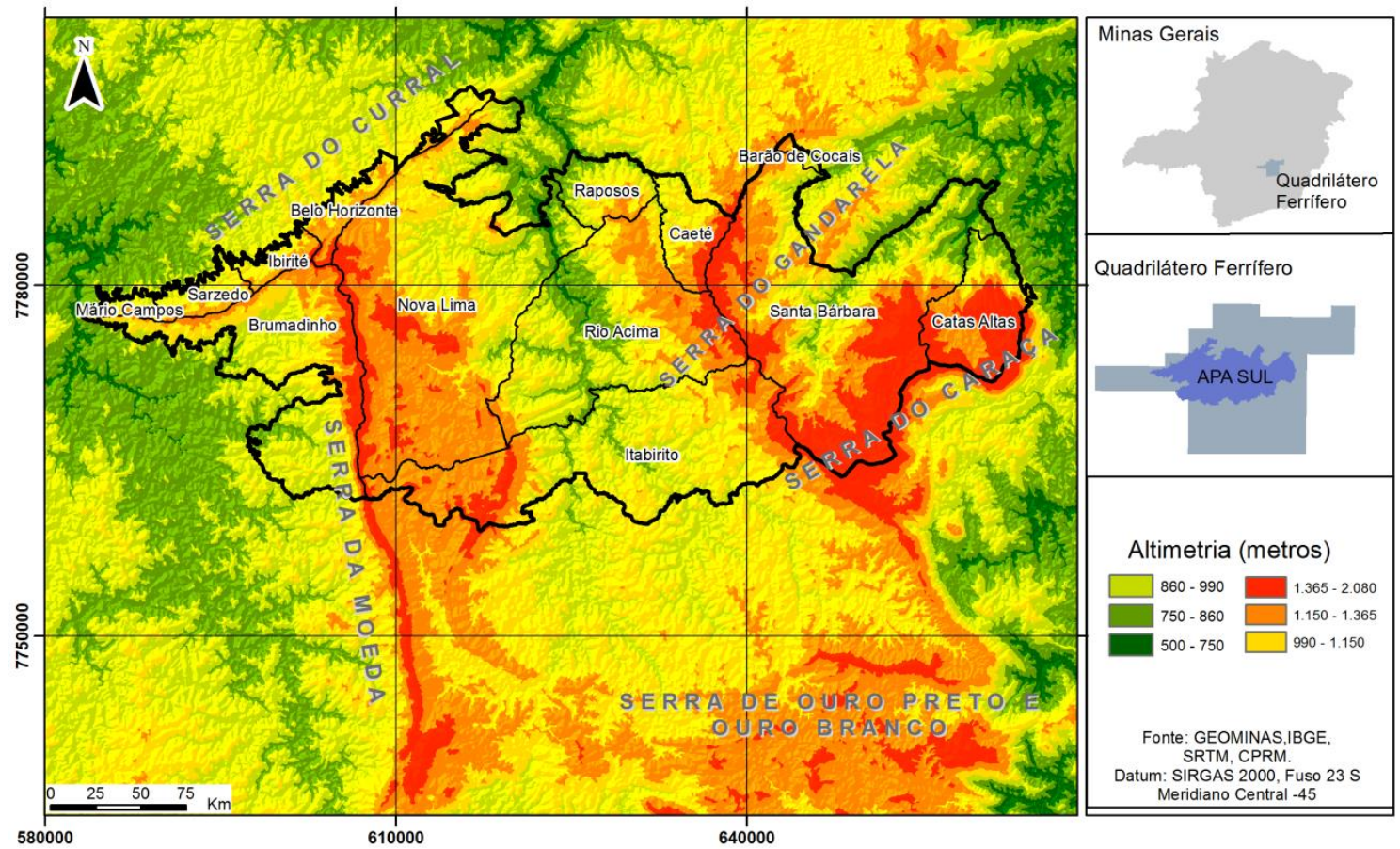

Figura 1: Mapa de localização da APA Sul da RMBH com os limites dos municípios que a integram. Fonte: Organizado pelos autores.

A área de estudo encerra um rico patrimônio natural e cultural e abriga importantes áreas de lavra, relacionadas, principalmente, à exploração de ouro e ferro. A APA Sul da RMBH foi transformada em Unidade de Conservação pelo Decreto Estadual № 35.624, de junho de 1994, que teve alterações em 1996, por meio do Decreto Estadual oㅜ 37.812. A redação final foi feita na Lei Estadual no 13.960, de 26 de julho de 2001.

Geologicamente é caracterizada por três grandes conjuntos de rochas: complexos metamórficos de rochas cristalinas arqueanas; sequências do tipo greenstone belt arqueana representada pelo Supergrupo Rio das Velhas; e sequências metassedimentares paleo e mesoproterozóicas representadas pelo Supergrupo Minas, Grupo Sabará, Grupo Itacolomi e Supergrupo Espinhaço. Ainda ocorrem na região bacias sedimentares terciárias, além de intrusões posteriores à formação do Supergrupo Minas sem uma datação precisa.

A geomorfologia é bastante diversificada, apresenta uma grande quantidade de formas e processos, diretamente associados às suas características litológicas, estruturais e pela ação da erosão diferencial. Todo o conjunto está sobrelevado, com intervalo de altitude, predominantemente, entre 900 e 1500 metros. Em relação aos solos, de acordo com Carvalho Filho et al. 
(2010), a área do QF é marcada pelo predomínio de solos pouco evoluídos (cambissolos e neossolos litólicos), ocorrem ainda latossolos, argissolos; no topo das serras do Curral, Moeda, Rola Moça e Gandarela, bem como materiais concrecionais como as cangas lateríticas, as plíntitas e petroplíntitas.

\section{MATERIAIS E MÉTODOS}

O método utilizado para o cálculo da geodiversidade neste artigo baseou-se na proposta apresentada por Serrano e Ruiz-Flaño (2007). Os procedimentos metodológicos dividiram-se em três etapas: tratamento da base de dados, cálculo do índice de geodiversidade e seleção de geossítios para o geoturismo.

\subsection{Tratamento da base de dados}

Foram usadas as bases cartográficas provenientes do Projeto APA Sul da $\mathrm{RMBH}$, publicado em 2005, originalmente em escala 1:50.000: mapa geológico, mapa pedológico, mapa geomorfológico e mapa hidrogeológico.

Essas bases necessitaram passar por uma série de tratamentos que foram realizados no software ArcGis 10.1 e incluíram: (a) reprojeção para o Sistema de Referência Geocêntrico para as Américas 2000 (SIRGAS 2000); (b) dissociação das classes de cada uma das variáveis escolhidas e exclusão daquelas que não seriam utilizadas; (c) atribuição de valores a cada uma das classes e a feição de limite da área de estudo; (d) união de cada uma das feições ao limite da área de estudo; (e) a conversão dos dados do formato vetorial para raster.

\subsection{Cálculo do índice de geodiversidade}

Foram usadas seis variáveis com seu respectivo número de feições: litologia (44), idade geológica (4), unidades do solo (22), unidades de relevo (16), unidades morfológicas (12) e unidades hidrogeológicas (9). As variáveis utilizadas no cruzamento final totalizaram 107 elementos distintos. Pereira et al. (2013), apresentaram uma modelagem da geodiversidade da APA Sul da RMBH e, nesta publicação, os autores incluíram, além das variáveis descritas, a variável ocorrências minerais com 12 feições e a variável rugosidade. Segundo os autores os resultados não foram satisfatórios, pois a adição de 
uma feição pontual, ocorrências minerais, superestimou a geodiversidade da área de estudo.

O índice de Geodiversidade foi calculado a partir da adaptação da equação (1) de Serrano e Ruiz-Flaño (2007):

$$
\mathrm{G}=(\mathrm{N}) /(\mathrm{S}) \quad \text { Equação (1) }
$$

Onde $\mathrm{N}$ corresponde ao número de elementos físicos de cada área e S à superfície real.

\subsection{Seleção de geossítios}

A escolha dos sítios da geodiversidade considerou os seguintes critérios: área classificada como de muito alta geodiversidade; diversidade paisagística e análise do contexto cênico; facilidade de acesso e deslocamento. O primeiro critério foi analisado a partir do resultado do mapa síntese dos índices de geodiversidade da APA Sul da RMBH que direcionou a etapa de campo onde os dois últimos critérios foram analisados.

Os sítios selecionados foram assim denominados: Gandarela, Cachoeiras do Viana/Índio, Alto Mingu e Mineração Ferrífera. Seu inventário teve como referência as recomendações da Comissão Brasileira de Sítios Geológicos e Paleontológicos (SIGEP) além de descrever as variáveis ambientais de cada sítio.

\section{RESULTADOS E DISCUSSÃO}

\section{1. Índices de geodiversidade}

O resultado obtido a partir da aplicação do algoritmo que gerou os índices de geodiversidade da APA Sul da RMBH é apresentado na Figura 2. Após contagem do número de feições em cada variável, os valores variaram de 3 a 8 . Em termos gerais, os valores de geodiversidade são relativamente altos, já que $96 \%$ da área apresenta valores entre 6 e 8 . Para facilitar a análise dos resultados, os dados foram apresentados de forma temática em quatro classes de geodiversidade: baixa, média, alta e muito alta. 


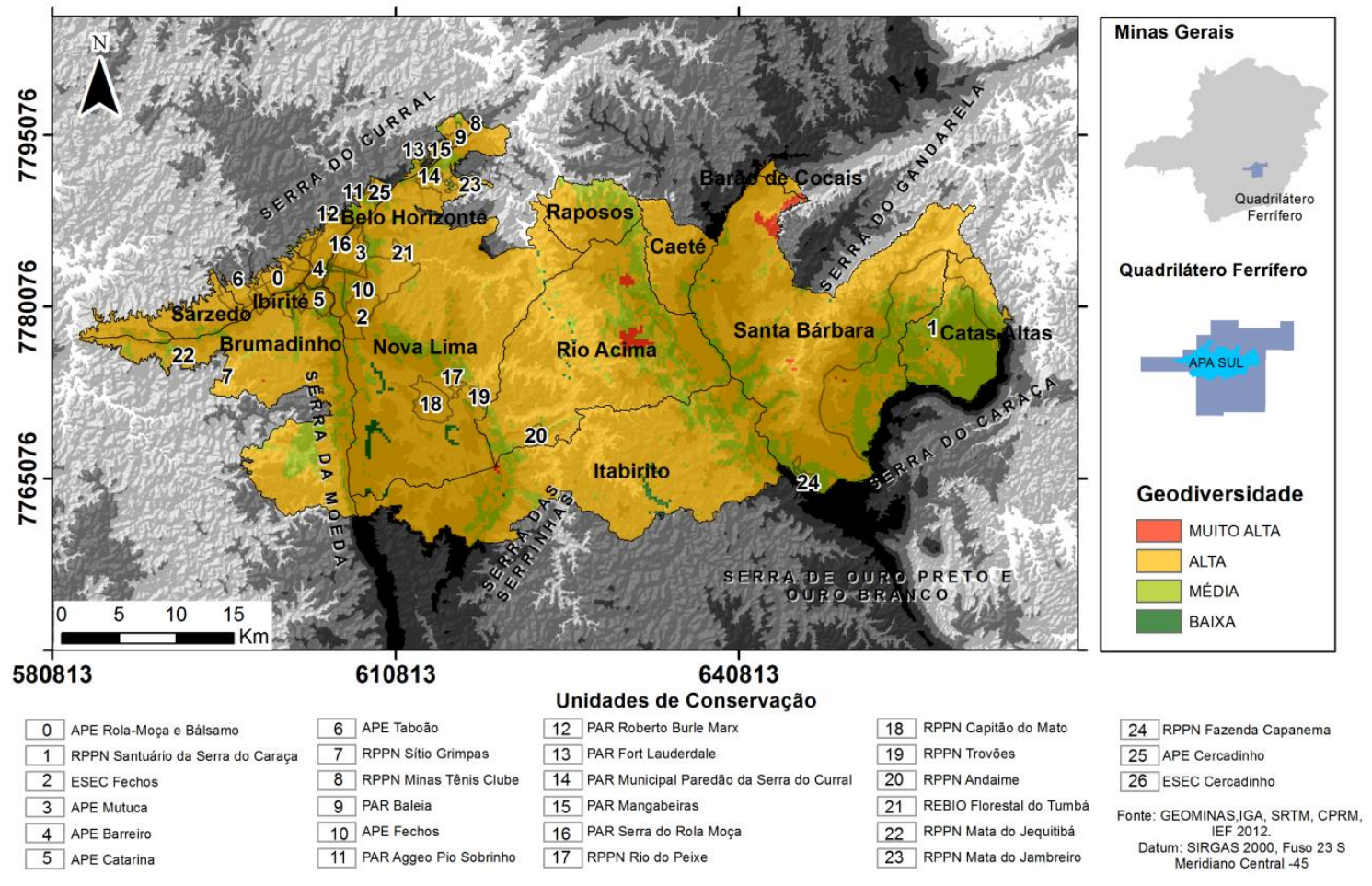

Figura 2: Mapa de geodiversidade da APA Sul RMBH e sua relação com as Áreas de Proteção Especial (APE) e com as unidades de conservação de diferentes categorias de manejo. Fonte: Elaborado pelos autores.

A geodiversidade é baixa em apenas $1 \%$ da área e concentra-se nos municípios de Nova Lima e Itabirito. Índices de média, alta e muito alta geodiversidade estão presentes em todos os municípios da APA Sul da RMBH e correspondem a aproximadamente 6\%, 90\% e 3\% da área, respectivamente. Grande parte das áreas classificadas como de média e alta geodiversidade correspondem à serra do Curral, onde ocorre uma série de Áreas de Proteção Especial (APE), cuja principal função é a manutenção dos mananciais que abastecem a capital mineira. Além destas áreas protegidas destacam-se ainda duas unidades de conservação municipais: o Parque das Mangabeiras (1966) e o Parque Paredão da Serra (2008); e uma unidade de conservação estadual: o Parque Estadual da Serra do Rola Moça (1994). Nestas áreas a geodiversidade tem garantida sua proteção já que são unidades de conservação classificadas como de proteção integral.

A geodiversidade apresenta os maiores índices (classificados como de muito alta geodiversidade) nos municípios de Rio Acima, Santa Bárbara e 
Itabirito, correspondendo a 3\% da área. Nestas regiões foram selecionados os quatro sítios da geodiversidade de interesse para o desenvolvimento do geoturismo (Figura 3).

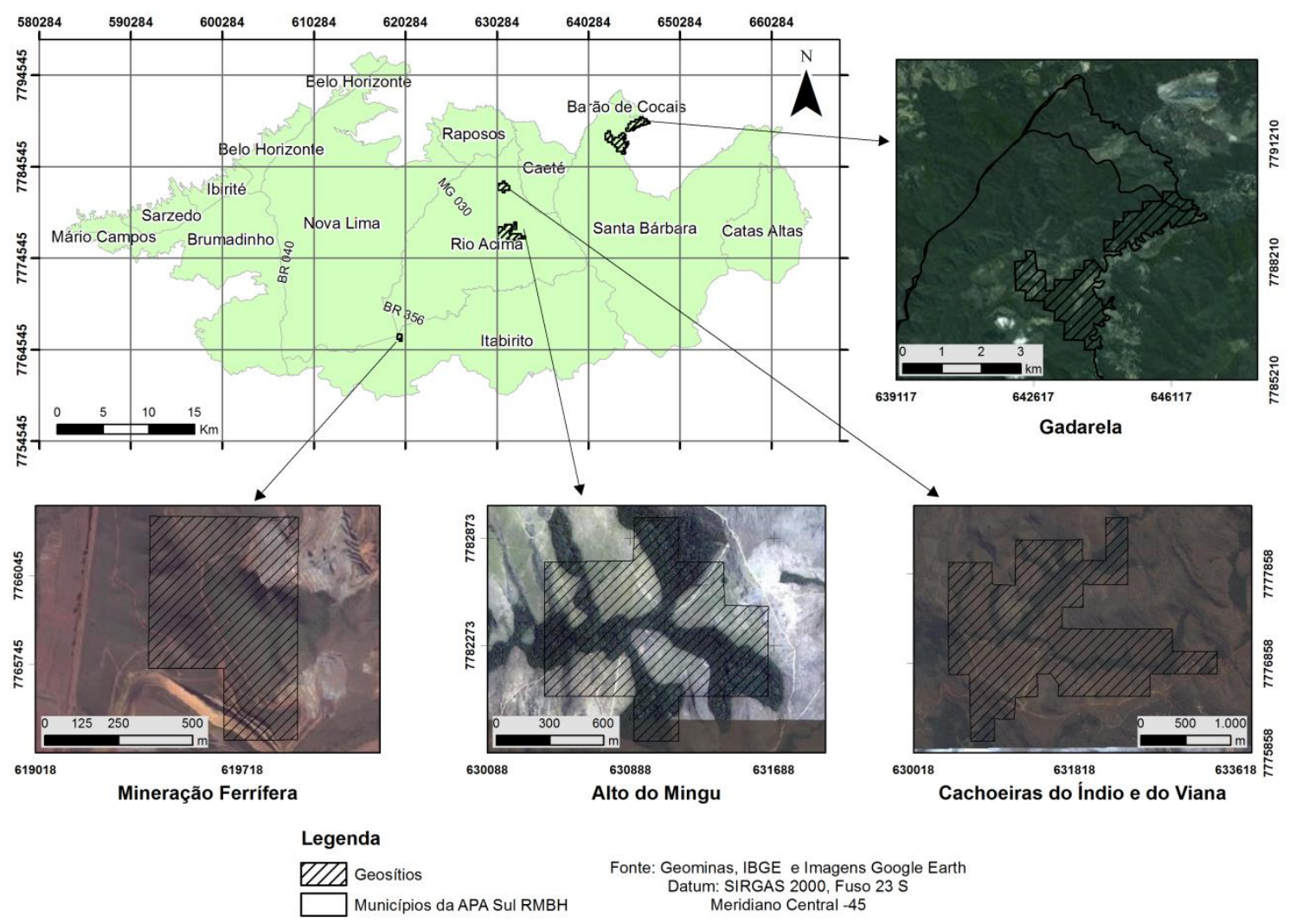

Figura 3: Áreas de maior geodiversidade da APA Sul da RMBH selecionadas para o desenvolvimento prioritário do geoturismo. Fonte: Elaborado pelos autores.

\subsection{Sítio da geodiversidade Gandarela}

O sítio da geodiversidade Gandarela corresponde à parte da serra homônima, importante patrimônio natural, cujas altitudes variam de 800 a 1200 metros. Nesta porção, ocorrem várias cavidades naturais subterrâneas em rochas ferruginosas e a presença de significativos mananciais de água, conforme salientado por Ruchkys et al. (2015a) com grande potencial educativo. Pereira (2014), Ruchkys (2015) e Ruchkys et al. (2015b) destacam ainda a ocorrência de canga que suporta uma vegetação característica dos campos rupestres ferruginosos. A presença das cangas que suportam o relevo 
permite contar parte da história de evolução geológica da região além de ter grande valor paisagístico e diversidade de plantas (Figuras 4a e 4b).

\subsection{Sítio da geodiversidade Cachoeiras do Índio e do Viana}

Este geossítio teve sua importância divulgada pelo Projeto Excursão Virtual pela Estrada Real no QF do Serviço Geológico do Brasil (CPRM). Nas Cachoeiras do Índio e do Viana ocorrem boas exposições dos quartzitos da Formação Palmital e metaconglomerados da Formação Casa Forte. Estas rochas correspondem à porção sedimentar do greenstone belt Rio das Velhas. O relevo é resultado da erosão diferencial que atua nas rochas o que favoreceu as rupturas de declive e a presença das cachoeiras. O ambiente fluvial encontra-se natural e bem preservado. Existe uma parte próxima às quedas d'água que permite avistar o Pico de Itabirito e a Serra do Curral (Figuras 4c e 4d).

\subsection{Sítio da geodiversidade do Alto Mingu}

Localizado em Rio Acima, esta área é marcada pela presença de cursos d'água bastante conservados que são captados para o abastecimento de sua sede municipal. O principal curso d’água é o córrego do Mingu, que dá nome ao sítio identificado. Colinas, platôs quartzíticos, serras e patamares, conferem diversidade ao relevo. Além disso, afloramentos rochosos e o leito rochoso dos rios são atrativos para o geoturismo também potencializado pela prática de mountainbike e de caminhada. No alto do Mingu encontra-se o Curralinho, marco inicial da história de construção de Rio Acima. A região foi protegida pela criação de uma Área de Proteção Ambiental municipal que leva o nome do córrego (Figuras 4e e 4f).

\subsection{Sítio da geodiversidade Mineração Ferrífera}

O sítio da geodiversidade Mineração Ferrífera, localizado no município de Itabirito é marcado pela presença maciça de áreas de mineração. A canga é marcante na paisagem, e, sem dúvida, o que mais chama a atenção é o Pico de Itabirito. Com seus 1.685 metros de altitude, foi reconhecido como marco 
estrutural, histórico e geográfico pela Comissão Brasileira de Sítios Geológicos e Paleobiológicos - SIGEP (Rosière et al., 2009), além de ser um dos sítios geológicos descritos por Ruchkys (2007, 2009). A história geológica e de exploração do pico merece ser traduzida para o público leigo, essa é a localidade-tipo onde foi definido o termo "itabirito" por Eschwege, no início do século XIX. Ele é constituído por minério de ferro compacto pertencente à Formação Cauê, Grupo Itabira, Supergrupo Minas, sua exploração teve início na década de 1940 e a mineração, ativa desde então, vem modificando a paisagem (Figuras $4 \mathrm{~g}$ e $4 \mathrm{~h}$ ).
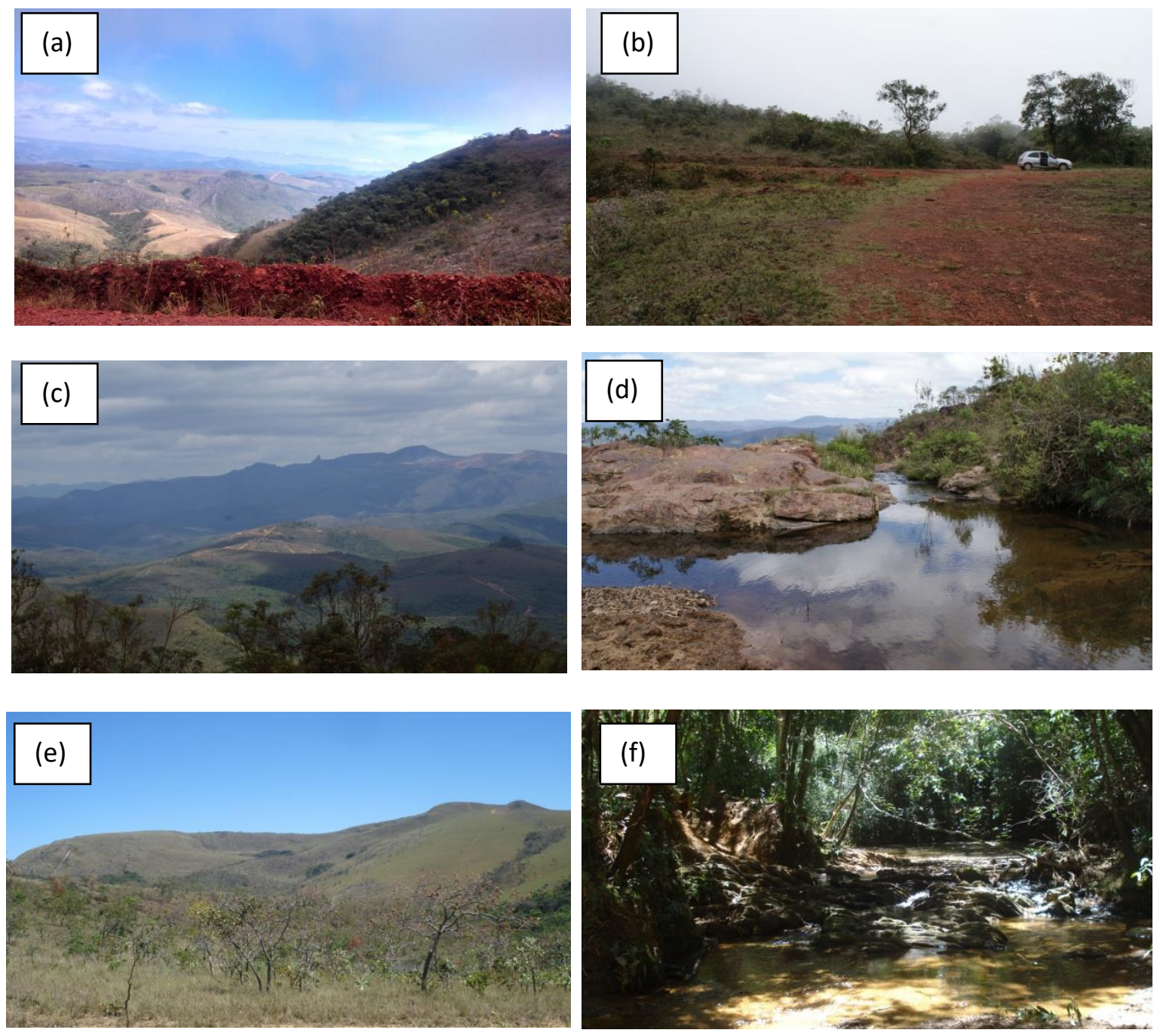

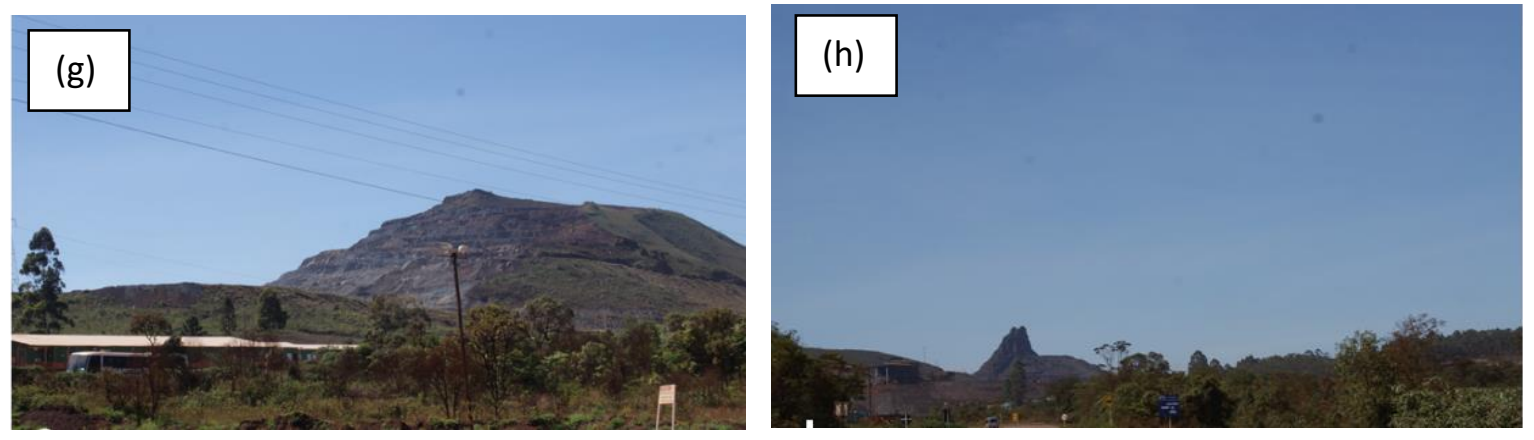

Figura 4: Registros fotográficos (a) e (b) Sítio da geodiversidade Gandarela: em (a) vista cênica a partir do sítio e em (b) destaque para a carapaça ferruginosa de canga; (c) e (d) Sítio da geodiversidade Cachoeiras do Índio e do Viana: em (c) vista cênica a partir do sítio de onde pode ser avistado o Pico de Itabirito e em (d) poço formado a montante da cachoeira do Viana; (e) e (f) Sítio da geodiversidade do Alto Mingu: em (e) destaque para as colinas e platôs quartzitícos que caracterizam a paisagem e em (f) córrego Mingu com seu leito rochoso; (g) e (h) Sítio da geodiversidade Mineração Ferrífera: em (g) vista lateral da mina do Pico e em (h) o Pico de Itabirito que se destaca na paisagem. Fonte: Fotos dos autores.

\section{CONSIDERAÇÕES FINAIS}

A APA Sul da RMBH é uma importante unidade de conservação do Quadrilátero Ferrífero e seu planejamento e gestão devem considerar ações que valorizem seu geopatrimônio por meio de práticas educativas e conservacionistas como é o caso do geoturismo. Para tanto é necessário o desenvolvimento de inventários e caracterização dos potenciais atrativos relacionados aos elementos do meio abiótico, o que pode ter custos elevados em se tratando de grandes áreas.

A realização desse trabalho foi baseada em uma abordagem de cunho geográfico, por meio do cálculo de índices de diversidade natural com técnicas de geoprocessamento. Os índices de diversidade natural aplicados aos elementos do meio abiótico têm sido utilizados para quantificar a geodiversidade. No caso da APA Sul da RMBH a aplicação do método se mostrou eficiente e a representação da geodiversidade, por meio de um mapa com cinco diferentes classes serviu, em um primeiro momento, para mostrar a variação quantitativa, em termos de riqueza dos elementos analisados (litologia, idade geológica, unidades do solo, unidades de relevo, unidades morfológicas e unidades hidrogeológicas) e sua distribuição espacial.

Os resultados obtidos revelaram as regiões com maior variedade natural em termos dos elementos abióticos da natureza onde foram selecionados 
geossítios prioritários para o desenvolvimento do geoturismo. Os resultados foram tão satisfatórios que houve, inclusive, a coincidência de duas áreas classificadas como de muito alta geodiversidade com sítios já descritos na literatura pela sua importância patrimonial: Sítio da geodiversidade Cachoeiras do Índio e do Viana e Sítio da Geodiversidade Mineração Ferrífera.

Sugere-se que as prefeituras que tiveram áreas classificadas como de mais alta geodiversidade disponibilizem recursos para levantamentos cartográficos de maior detalhe em relação aos aspectos do meio abiótico permitindo melhor conhecimento de seu território. As áreas indicadas como de muito alta geodiversidade podem ser utilizadas com o subsídio à justificativa para criação de unidades de conservação de proteção integral onde a prática do geoturismo é permitida e pode ser desenvolvida de forma integrada com a educação ambiental.

Acredita-se que o método aqui aplicado possa ser replicado no mapeamento da geodiversidade de outras regiões desde que exista disponibilização de bases em escala adequada. Sua utilização pode indicar áreas com maior potencial de se encontrar sítios da geodiversidade de interesse geoturístico minimizando esforços de campo e de inventariação.

\section{REFERÊNCIAS}

ARRUDA, K. E. Geodiversidade do município de Araripina - PE, Nordeste do Brasil. 2013. 171 f. Dissertação (Mestrado em Geografia) Departamento de Geografia, Universidade Federal de Pernambuco, Recife.

BENTO, L. C. M.; RODRIGUES, S. C. Geoturismo nas quedas d'Água do município de Indianápolis. Revista Mercator, Fortaleza, v. 10, n. 21, p. 147160, 2011.

BENTO, L. C. M.; RODRIGUES, S. C. Geoturismo em unidades de conservação: uma nova tendência ou uma necessidade real? Revista do Departamento de Geografia - USP, São Paulo, v. 25, p. 77-97, 2013.

BENTO, L. C. M.; ARAUJO, M. S.; RODRIGUES, G. S. S. C.; da SILVA, V. P. Potencial geoturístico das quedas d'água de Indianópolis-MG para o público escolar: unindo ciência e contemplação. Anuário do Instituto de Geociências, Rio de Janeiro, v.35, p.152-164, 2012. 
QUANTIFICAÇÃO E ANÁLISE DA GEODIVERSIDADE APLICADA AO GEOTURISMO NA ÁREA DE PROTEÇÃO AMBIENTAL SUL DA REGIÃO METROPOLITANA DE BELO HORIZONTE, MINAS GERAIS

BORBA, A. W. Geodiversidade e geopatrimônio como bases para estratégias de geoconservação: conceitos, abordagens, métodos de avaliação e aplicabilidade no contexto do Estado do Rio Grande do Sul. Pesquisas em Geociências, Porto Alegre, v.38, n.1, p. 3-13, 2011.

BRILHA, J. Inventory and quantitative assessment of geosites and geodiversity sites: a review. Geoheritage, Springer Berlin Heidelberg, p. 1-16, 2015. Disponível em: <http://link.springer.com/article/10.1007\%2Fs12371-0140139-3\#/page-1>. Acesso em: 30 de out. 2015.

BUREK, C.; POTTER, J. Local geodiversity action plans. Setting the context for geological conservation. BioScience, Uberlândia, v. 52, n. 6, p. 499-512, 2002.

CAMPELLO, M. S.; RUCHKYS, U. A.; HADDAD, E. A.; MACHADO, M.M.M. Cavidades naturais da Pedra Grande de Igarapé - geossítio de relevância espeleológica do Quadrilátero Ferrífero, Minas Gerais. Anuário do Instituto de Geociências, Rio de Janeiro, v.35, p.252-260, 2012.

CARCAVILLA URQUI, L. Patrimonio geologico y geodivesidad: investigaciòn, conservaciòn, gestiòn $y$ relaciòn con los espacios naturales protegidos. 2006. 339 f. Tese (Doutorado em Geografia) Universidad Autonoma de Madrid, Madrid.

CARVALHO FILHO, A.; CURI, N.; SHINZATO, E. Relações solopaisagem no Quadrilátero Ferrífero, MG. Pesquisa Agropecuária Brasileira, Brasília, v.45, p.903-916, 2010.

CPRM - Serviço Geológico do Brasil. Mapa geodiversidade do Brasil. Brasília: Serviço Geológico do Brasil, 2006. 68 p.

GORENSTEIN, M. R. Diversidade de espécies em comunidades arbóreas: aplicação de índices de distinção taxonômica em três formações florestais do Estado de São Paulo. 2009. 146 f. Tese (Doutorado em Recursos Florestais) - Escola Superior de Agricultura, Universidade de São Paulo, São Paulo.

GRAY, M. Geodiversity: valuing and conserving abiotic nature. Chichester-England: John, Wiley \& Sons, 434 p, 2004.

HJORT, J.; LUOTO, M. Geodiversity of high-latitude landscapes in northern Finland. Elsevier Geomorphology, Melbourne, v. 115, p. 109-116, 2010.

HOSE, T.A. European "geotourism" - geological interpretation and geoconservation promotion for tourists. In: BARRETINO, D; WINBLEDON, W.A.P.; GALLEGO, E. (eds). Geological heritage: its conservation and 
management. Madrid: Instituto Tecnológico e GeoMinero da España, 2000, p. 127-146.

HOSE, T.A. Selling the story of britain's stone. Environmental Interpretation, v. 10, p. 16-17, 1995.

KOZLOWSKI, S. The concept and scope of geodiversity. Przegld Geologiczny, v. 52, n. 8/2, p. 833-837, 2004. Disponível em: < https://www2.pgi.gov.pl/images/stories/przeglad/pdf/pg_2004_08_2_22a.pdf>. Acesso em: 20 de nov. 2015.

LICCARDO, A.; BARBOSA, T.A.; HORNES, K.L. Diamante de Tibagi no Paraná - patrimônio geológico-mineiro e cultural. Anuário do Instituto de Geociências, Rio de Janeiro, v.35, n.1, p. 142-151, 2012.

LOBO, H. A. S.; BOGGIANI, P. C. Cavernas como patrimônio geológico. Boletim Paranaense de Geociências, Curitiba, v. 70, p. 190-199, 2013.

LOPES, L. S. O.; ARAUJO, J. L. L.; NASCIMENTO, M. A. L. Valores de uso turístico dos geossítios de Sete Cidades (PI). Anuário do Instituto de Geociências, Rio de Janeiro, v.35, n.1, p.209-221, 2012. DOI: http://dx.doi.org/10.11137/2012_1_209_221.

MANOSSO, F. C.; ONDICOL, R. P. Geodiversidade: considerações sobre quantificação e avaliação da distribuição espacial. Anuário do Instituto de Geociências, Rio de Janeiro, v.35, n.1, p. 90-100, 2012 . DOl: http://dx.doi.org/10.11137/2012_1_90_100.

MANSUR, K. L.; ROCHA, A. J. D.; PEDREIRA, A.; SCHOBBENHAUS, C.; SALAMUNI, E.; COSTA E., F. Iniciativas institucionais de valorização do patrimônio geológico do Brasil. Boletim Paranaense de Geociências, Curitiba, v. 70 , p. 2-27, 2013.

MANTESSO-NETO, V.; MANSUR, K. L.; RUCHKYS, U.; NASCIMENTO, M. A. L. O que há de geológico nos atrativos turísticos convencionais no Brasil. Anuário do Instituto de Geociências, Rio de Janeiro, v.35, n.1, p. 49-57, 2012. DOI: http://dx.doi.org/10.11137/2012_1_49_57.

MOREIRA, J. C. Interpretative panels about the geological heritage - a case study at the Iguassu Falls National Park (Brazil). Geoheritage, v.4, p. 127-137, 2012. DOI 10.1007/s12371-012-0053-5.

OLIVEIRA, P. C. A.; de SOUSA PEDROSA, A.; RODRIGUES, S. C. Uma abordagem inicial sobre os conceitos de geodiversidade, geoconservação e patrimônio geomorfológico. Ra'eGa O Espaço Geográfico em Análise, Curitiba, v.29, n.1, p. 92-114, 2013. Disponível em: $<$ http://ojs.c3sl.ufpr.br/ojs/index.php/raega/article/view/30083/21475>. Acesso em: 20 de out. 2015. 
QUANTIFICAÇÃO E ANÁLISE DA GEODIVERSIDADE APLICADA AO GEOTURISMO NA ÁREA DE PROTEÇÃO AMBIENTAL SUL DA REGIÃO METROPOLITANA DE BELO HORIZONTE, MINAS GERAIS

OStANELlO, M. C. P.; DANDERFER, A.; CAStRO, P. T. A. Caracterização de lugares de interesse geológico e trilhas geoturísticas no Parque Estadual do Itacolomi - Ouro Preto e Mariana, Minas Gerais. Geociências, São Paulo, v. 32, n.2, p.286-297, 2012. Disponível em: $<$ http://ppegeo.igc.usp.br/scielo.php?pid=S0101-

90822013000200006\&script=sci arttext>. Acesso em: 02 de out. 2015.

PEREIRA, E. O. Modelagem da Geodiversidade da Área de Proteção Ambiental Sul da Região Metropolitana de Belo Horizonte. 2014. $80 \mathrm{f}$. Dissertação (Mestrado em Análise e Modelagem de Sistemas Ambientais) Departamento de Cartografia, Universidade Federal de Minas Gerais, Belo Horizonte.

PEREIRA, E.O.; RUCHKYS, U.A.; PELLITERO, R.O. Modelagem da Geodiversidade da Área de Proteção Ambiental Sul da Região Metropolitana de Belo Horizonte. Geonomos, Belo Horizonte, v. 21, n. 2, p. 97-101, 2013. Disponível

em:< http://www.igc.ufmg.br/portaldeperiodicos/index.php/geonomos/article/view/277 >. Acesso em 03 de nov. 2015.

Rosière, C. A.; ReNGeR, F. E.; PIUZANA, D.; SPIER, C. A. Pico de Itabira, MG - marco estrutural, histórico e geográfico do Quadrilátero Ferrífero. In: WINGE M.; SCHOBBENHAUS C.; BERBERT-BORN M.; QUEIROZ E. T.; CAMPOS D. A.; SOUZA C. R. G.; FERNANDES A. C .S. (eds.). Sítios Geológicos e Paleontológicos do Brasil. Brasília: Comissão Brasileira de Sítios Geológicos e Paleobiológicos, 2009, p. 1-11.

RUBAN, D. A. Geotourism: a geographical review of the literature. Tourism Management Perspectives, v.15, p. 1-15, 2015. Disponível em: $<\mathrm{http}: / /$ www.researchgate.net/publication/274196862 Geotourism A geograp hical review of the literature>. Acesso em: 15 de mai. 2015.

RUCHKYS, U. A. Geoparques e a musealização do território: um estudo sobre o Quadrilátero Ferrífero. Revista do Instituto de Geociências da USP, São Paulo, v.5, p.35-46, 2009. DOI: http://dx.doi.org/10.11606/issn.23169087.v5i0p35-46.

RUCHKYS, U. A.; MACHADO, M. M. M. Patrimônio geológico e mineiro do Quadrilátero Ferrífero, Minas Gerais - caracterização e iniciativas de uso para educação e geoturismo. Boletim Paranaense de Geociências, Curitiba, v.70, p. 120-133, 2013. DOI: http://dx.doi.org/10.5380/geo.v70i0.31541.

RUCHKYS, U.A. Patrimônio geológico e geoconservação no Quadrilátero Ferrífero, Minas Gerais: potencial para criação de um geoparque da UNESCO. 2007. 211 f. Tese (Doutorado em Geologia) Departamento de Geologia, Universidade Federal de Minas Gerais, Belo Horizonte. 
QUANTIFICAÇÃO E ANÁLISE DA GEODIVERSIDADE APLICADA AO GEOTURISMO NA ÁREA DE PROTEÇÃO AMBIENTAL SUL DA REGIÃO METROPOLITANA DE BELO HORIZONTE, MINAS GERAIS

RUCHKYS, U.A. Sítios geológicos e propostas brasileiras de geoparques em geossistemas ferruginosos. In: CARMO, F.F.; KAMINO, L. H. Y. (Orgs.) Geossistemas ferruginosos do Brasil. Belo Horizonte: Editora 3i, 2015, p. 169-194.

RUCHKYS, U.A.; AZEVEDO, D.T.; MACHADO, M.M.M. Patrimônio ambiental da Serra da Moeda sob a ótica da geodiversidade. In: BAETA, A. e PILÓ, H. Serra da Moeda: patrimônio e história. Belo Horizonte: Orange Editorial, 2015a. p. 10-29.

RUCHKYS, U.A.; PEREIRA, E.; PEREIRA, M.C. Áreas prioritárias para geoconservação do patrimônio espeleológico em rochas ferruginosas do Quadrilátero Ferrífero. In: RUCHKYS, U.A.; TRAVASSOS, L.P.; RASTEIRO, M.A.; FARIA, L.E. Patrimônio espeleológico em rochas ferruginosas: propostas para sua conservação no Quadrilátero Ferrífero, Minas Gerais. Campinas: Sociedade Brasileira de Espeleologia, 2015b, p. 288-315.

SALAMUNI, E.; NASCIMENTO, E. R.; SILVA, P. A. H.; QUEIROZ, G. L.; SILVA, G. Knickpoint finder: tool for searching geosites of relevant interest for geotourism. Boletim Paranaense de Geociências, Curitiba, v.70, p.200-208, 2013. <http://ojs.c3sl.ufpr.br/ojs/index.php/geociencias/article/viewFile/32797/21560>. Acesso em: 06 de jun. 2015.

SERRANO, E.; RUIZ-FLAÑO, P. Geodiversidad: concepto, evaluación y aplicación terrotorial. El caso de Tiermes Caracena (Soria). Boletín de la Asociación de los Geógrafos Españoles, Madrid, v.45, p.79-98, 2007.

SILVA, J.P. Avaliação da diversidade de padrões de canais fluviais e da geodiversidade na Amazônia - aplicação e discussão na bacia hidrográfica do Rio Xingu. 2012. 277 f. Tese (Doutorado em Geografia) Faculdade de Filosofia, Letras e Ciências Humanas, Departamento de Ciências Humanas, Universidade de São Paulo, São Paulo.

SILVA, J. R. B.; PERINOTTO J. A. J. O geoturismo na geodiversidade de Paraguaçu Paulista como modelo de geoconservação das estâncias. Revista Global Tourism, v. 3, n. 2, 40 p., 2007.

STANLEY, M. Geodiversity. Earth Heritage, London, v.14, p.15-18, 2000.

VEIGA, A. T. A geodiversidade e o uso dos recursos minerais da Amazônia, Terra das Águas, Brasília, v.1, p.88-102, 1999.

XAVIER-DA-SILVA, J. J.; PERSSON, V. G.; LORINI, M. L.; BERGAMO, R. B. A.; RIBEIRO, M. F.; COSTA, A. J. S. T.; ABDO, O. E. Índices de geodiversidade: aplicações de SIG em estudos de biodiversidade. In: GARAY, I.; DIAS, B. F. S. (Orgs.). Conservação da biodiversidade em ecossistemas 
QUANTIFICAÇÃO E ANÁLISE DA GEODIVERSIDADE APLICADA AO GEOTURISMO NA ÁREA DE PROTEÇÃO AMBIENTAL SUL DA REGIÃO METROPOLITANA DE BELO HORIZONTE, MINAS GERAIS

tropicais: avanços conceituais e revisão novas metodologias de avaliação e monitoramento. Rio de Janeiro: Vozes, 2001, p. 299-316. 